\title{
Comparison of Transbronchial Lung Biopsy Yield between Standard Forceps and Electrocautery Hot Forceps in Swine
}

\author{
Momen M. Wahidi ${ }^{a}$ Scott L. Shofer ${ }^{a}$ Thomas A. Sporn ${ }^{b}$ Armin Ernst ${ }^{c}$ \\ a Division of Pulmonary and Critical Care Medicine, Department of Internal Medicine, and bepartment of \\ Pathology, Duke University Medical Center, Durham, N.C., and ' Division of Pulmonary and Critical Care Medicine, \\ Department of Internal Medicine, Beth Israel Deaconess Medical Center, Boston, Mass., USA
}

\section{Key Words}

Bronchoscopy · Transbronchial lung biopsy •

Electrocautery

\begin{abstract}
Background: Transbronchial lung biopsy (TBLB) is a commonly performed bronchoscopic procedure. Previous studies have suggested that larger biopsy forceps may improve diagnostic yield; however, the risk of bleeding associated with larger samples may be increased. The hot forceps are large forceps that are connected to an electrocautery system to minimize bleeding at the time of biopsy. Objectives: We evaluated the hot forceps for improvement in biopsy size and the number of sampled alveoli. Methods: TBLBs were performed in 2 swine using one type of the forceps, followed by the other forceps $24 \mathrm{~h}$ later. Electrocautery was applied from closure of the forceps to retrieval of the sample. A blinded pathologist measured the size of each sample in its longest dimension and calculated the total alveolar content within the largest cross-section from each biopsy. Results: A total of 74 biopsies were collected using each forceps type. Alveolar tissue was present in $25 / 74$ and $26 / 74$ of the biopsies using the hot and conventional forceps, re-
\end{abstract}

spectively. There was no difference in the size of biopsies collected $(2.10 \pm 1.10$ vs. $1.83 \pm 0.94 \mathrm{~mm} ; \mathrm{p}=0.164)$ or in the amount of alveoli per sample (343.2 \pm 402.4 vs. 439.5 \pm 463.5 alveoli; $p=0.433$ ) for hot and conventional forceps, respectively. There was no artifact related to the use of electrocautery, and bleeding was minimal using either forceps system. Conclusions: The use of the electrocautery hot forceps for TBLB did not result in improvement of the size of biopsies or the amount of collected alveolar tissue in healthy pigs.

Copyright $\odot 2009$ S. Karger AG, Basel

\section{Introduction}

Flexible bronchoscopy with transbronchial lung biopsy (TBLB) is a commonly used technique in pulmonary medicine for the diagnosis of a wide variety of diseases. However, one of the limiting features of this technique is the small sample obtained using conventional forceps [1]. Previous studies have suggested that larger forceps may improve diagnostic yield; however, as forceps become larger, there is greater concern about the development of complications, particularly bleeding [2-

\section{KARGER}

Fax +41613061234 E-Mail karger@karger.ch www.karger.com (c) 2009 S. Karger AG, Basel

0025-7931/10/0792-0137\$26.00/0

Accessible online at:

www.karger.com/res
Momen M. Wahidi, MD, MBA

Interventional Pulmonology, Division of Pulmonary and Critical Care Medicine

Duke University Medical Center, Box 3683

Durham, NC 27710 (USA)

Tel. +1 919668 0340, Fax +1 919684 3874, E-Mail momen.wahidi@duke.edu 
4]. In recent years, larger forceps connected to an electrocautery system, named the 'hot forceps', were designed for use with flexible bronchoscopy. With these forceps, heat energy is delivered after grasping the tissue to promote coagulation and reduce bleeding at the time of tissue collection. A recent study evaluated these hot forceps for biopsies of endobronchial lesions and showed no difference in diagnostic yield and a small improvement in bleeding compared with conventional forceps [5]. No data are available regarding the use of these forceps for TBLBs. The objective of our study is to evaluate the hot forceps for improvement in the size of biopsies or the amount of collected alveolar tissue per sample.

\section{Methods}

\section{Study Design}

This investigation was designed as a cross-over blinded study. The pathologist assessing the histological biopsy samples was blinded to the type of forceps used during the experiment. The main outcome was the quantity of lung tissue, macroscopically and microscopically, obtained with TBLB.

\section{Animals}

The experiment protocol was approved by the Duke University Institutional Animal Care and Use Committee. The experiment was conducted in accordance with the National Research Council guidelines. Yorkshire swine were used for the study due to similarity of lung anatomy and mucosal and tissue characteristics to those of humans [6]. Additionally, pig models have been used previously in bronchoscopy research on airway stenosis, malacia, airway stents and TBLB [7-10].

Animals were procured for medical purposes and were free of lung diseases. They were housed in the animal facility at Duke University and were quarantined for $48 \mathrm{~h}$ prior to study entry.

\section{Description of Procedure}

The procedure was performed after an overnight fast. Swine were sedated with acepromazine $1.1 \mathrm{mg} / \mathrm{kg}$ intramuscularly and ketamine $22 \mathrm{mg} / \mathrm{kg}$ intramuscularly followed by insertion of an intravenous catheter into an ear vein. Propofol $6 \mathrm{mg} / \mathrm{kg}$ intravenously was then administered to achieve deeper sedation. Animals were endotracheally intubated and ventilated using a Respironics Esprit ventilator (Respironics, Murraysville, Pa., USA) set to deliver a tidal volume of $8 \mathrm{ml} / \mathrm{kg}$ and an $\mathrm{O}_{2}$ saturation of $>95 \%$. Blood pressure, $\mathrm{O}_{2}$ saturation and electrocardiogram tracing were monitored continuously throughout the procedure. The swine were sacrificed after the biopsies were completed.

Two animals, of equal size and weight, were enrolled in the study. One animal underwent TBLB with the standard forceps followed by the hot forceps $24 \mathrm{~h}$ later, while the other animal underwent the procedure in the opposite order.

All procedures were performed using a Pentax bronchoscope (Pentax, Inc., Montvale, N.J., USA) dedicated for animal use.

The conventional forceps cups (Conmed Corporation, Utica, N.Y., USA) were $1.8 \mathrm{~mm}$ wide (diameter A) and $2 \mathrm{~mm}$ long (diam-

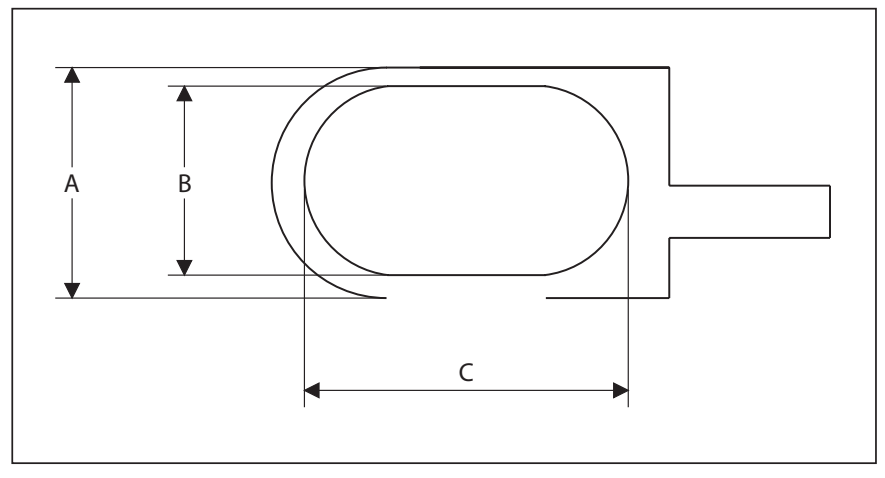

Fig. 1. Various dimensions (diameters A-C) for forceps cups.

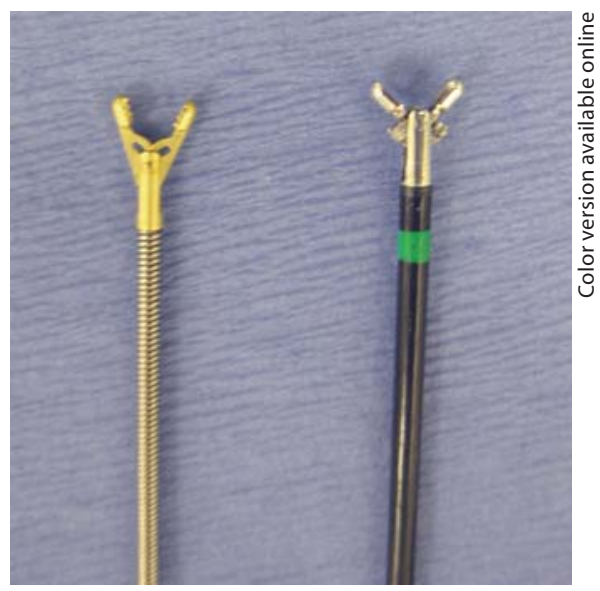

Fig. 2. Conventional (left) and hot electrocautery forceps (right).

eter C), with a total cup capacity of $3 \mathrm{~mm}^{3}$ (fig. 1, 2). The hot forceps cups (Olympus, Inc., Center Valley, Pa., USA) were $2.2 \mathrm{~mm}$ wide (diameter A) and $2.6 \mathrm{~mm}$ long (diameter C), with a total cup capacity of $5.1 \mathrm{~mm}^{3}$.

The bronchoscope was introduced via the endotracheal tube. The right caudal lobe was identified by visual inspection and the tip of the bronchoscope was placed in the wedge position. TBLBs were performed under fluoroscopic guidance using conventional or hot forceps. The conventional forceps were advanced under fluoroscopy to a peripheral region of the lung, opened, closed and retracted obtaining a tissue sample; the hot forceps were employed in a similar fashion to the conventional forceps with the exception that, after grasping the tissue with the forceps, electrocautery was activated for approximately $5 \mathrm{~s}$ prior to pulling the sample from the surrounding lung tissue. The electrocautery generator (Olympus, Inc., Center Valley, Pa., USA) was set to $40 \mathrm{~W}$ for each biopsy. Samples were placed in formalin and processed for histology per standard hospital protocol. Bleeding was assessed as none, mild, moderate or severe after each pass of the biopsy forceps. This was adopted from prior clinical studies and 
defines bleeding as follows: no bleeding = presence of only traces of blood after finishing the biopsies with no need for continued suctioning; mild bleeding = need for continued suctioning of blood from the airways after the procedure; moderate bleeding = need for intubation of the biopsied segment with the flexible bronchoscope into the wedge position; severe bleeding = need for additional interventions, such as placing a temporary bronchus blocker, or intubation of the main stem bronchus on the bleeding side [11].

\section{Histology}

All samples were cut in $6-\mu \mathrm{m}$ sections and stained with hematoxylin and eosin. A blinded pathologist (T.A.S.) examined all samples and measured each biopsy in the longest dimension. The areas of the biopsies containing alveolar tissue were identified and measured with an ocular micrometer, deriving an overall area of alveolar tissue (in $\mathrm{mm}^{2}$ ) for each biopsy. Examination of specimens at scanning magnification indicated a mean alveolar content of $61 \mathrm{alveoli} / \mathrm{mm}^{2}$. Alveoli were defined as sacs or alveoli proper bounded on at least 3 sides by septa. The alveolar content of each specimen was then determined as a function of mean alveolar content for the specimens in aggregate $\times$ area of alveolated tissue per biopsy. Each sample was assessed for artifact related to electrocautery application, which was noted as present or absent.

\section{Statistics}

All values are reported as means $\pm \mathrm{SD}$. The two-tailed t test was performed for comparisons between groups using the Statistics Toolbox for Matlab version 7.2 service pack 5 (Mathworks, Natick, Mass., USA). Differences were considered to be significant at a $\mathrm{p}$ value of $<0.05$.

\section{Results}

A total of 74 biopsies were collected using the different forceps types. Alveolar tissue was present in 25/74 and $26 / 74$ of the biopsies obtained using the hot and conventional forceps, respectively. There was no difference in the size of biopsies collected $(2.10 \pm 1.10$ vs. $1.83 \pm 0.94$ $\mathrm{mm} ; \mathrm{p}=0.164)$ or the amount of alveoli per sample $(343.2$ \pm 402.4 vs. $439.5 \pm 463.5$ alveoli; $\mathrm{p}=0.433$ ) for electrocautery and conventional forceps, respectively. There was no artifact related to the use of electrocautery, and bleeding was minimal using either forceps type.

\section{Discussion}

TBLB is a safe and effective method of diagnosing a variety of pulmonary conditions including infections, selected interstitial lung diseases, malignant neoplasms and lung transplant rejection [12]. Larger sample size is thought to have a greater diagnostic yield, although the use of larger forceps intuitively should lead to higher rates of significant bleeding and pneumothorax [3]. The ability to safely obtain a large lung tissue sample via TBLB would be a major advancement in the diagnosis of pulmonary diseases, particularly in interstitial lung disease, and would obviate the need to subject patients to surgical lung biopsy. A study by Babiak et al. [13] demonstrated the ability to obtain large lung tissue samples via TBLB using a cryoprobe with minimal side effects. Our study attempted to reach the same goal by using electrocauteryenabled large forceps to improve lung tissue sample size without increasing the risk.

We were unable to demonstrate a difference in biopsy size or alveolar content related to the use of the hot forceps. There are several possibilities as to why there was no discernable difference between the 2 forceps types: (1) the sampling area was limited to a specific region of the lung which may have resulted in anatomic structures limiting the opening of the forceps cups and restricting the sampling size; (2) swine, although thought to be a good model of human airways, may have differences in pulmonary anatomy which make them less amenable to TBLB, which is demonstrated by the low percentage of TBLB samples that had alveolar tissue, or (3) the variability in sample size is greater than any small improvement in sample size related to larger forceps, and a much larger study is needed to show the difference.

Significant bleeding is thought to occur in $1.9-8 \%$ of transbronchial biopsies due to the injury of a pulmonary arteriole by the biopsy forceps $[14,15]$. The theoretical advantage of the hot forceps is the reduction in bleeding complications related to the use of the electrocautery at the time of tissue sampling. In fact, a recent study using hot forceps for endobronchial biopsy of malignant lesions demonstrated a reduced, although clinically insignificant, reduction in bleeding [4]. We had no significant bleeding associated with the use of either forceps type. It is noteworthy that swine may not represent a good model for investigating bleeding related to TBLB. Previous studies investigating the association of bleeding with the use of clopidogrel and TBLB in swine showed no increased risk of bleeding, while subsequent studies in humans have established significantly more bleeding in patients taking clopidogrel at the time of TBLB $[10,11]$.

Although our study findings are negative, we believe that it is important to share these results with the scientific community in order to advance the research of TBLB. 
In conclusion, we have compared the use of conventional pulmonary forceps with larger electrocautery-enabled hot forceps for TBLB in swine. We found no improvement in sample size or size of alveolar tissue per sample when using the hot forceps. Further studies are needed to verify this finding in humans.

\section{Acknowledgment}

This study was supported by an educational grant from Olympus, Inc., Center Valley, Pa., USA.

\section{References}

1 Poletti V, Chilosi M, Olivieri D: Diagnostic invasive procedures in diffuse infiltrative lung diseases. Respiration 2004;71:107-119.

2 Aleva RM, Kraan J, Smith M, et al: Techniques in human airway inflammation: quantity and morphology of bronchial biopsy specimens taken by forceps of three sizes. Chest 1998;113:182-185.

-3 Loube DI, Johnson JE, Wiener D, et al: The effect of forceps size on the adequacy of specimens obtained by transbronchial biopsy. Am Rev Respir Dis 1993;148:1411-1413.

4 Casoni GL, Gurioli C, Chhajed PN, et al: The value of transbronchial lung biopsy using jumbo forceps via rigid bronchoscope in diffuse lung disease. Monaldi Arch Chest Dis 2008;69:59-64.

5 Tremblay A, Michaud G, Urbanski SJ: Hot biopsy forceps in the diagnosis of endobronchial lesions. Eur Respir J 2007;29:108-111.
6 Ram B, Oluwole M, Blair RL, et al: Surgical simulation: an animal tissue model for training in therapeutic and diagnostic bronchoscopy. J Laryngol Otol 1999;113:149-151.

7 Brickey DA, Lawlor DP: Transbronchial biopsy in the presence of profound elevation of the international normalized ratio. Chest 1999;115:1667-1671.

8 Hautmann H, Huber RM: Laser resistance of expandable metal stents in interventional bronchoscopy: an experimental evaluation. Lasers Surg Med 2001;29:70-72.

-9 Marquette $\mathrm{CH}$, Mensier E, Copin MC, et al: Experimental models of tracheobronchial stenoses: a useful tool for evaluating airway stents. Ann Thorac Surg 1995;60:651-656.

$\checkmark 10$ Wahidi MM, Garland R, Feller-Kopman D, et al: Effect of clopidogrel with and without aspirin on bleeding following transbronchial lung biopsy. Chest 2005;127:961-964.
11 Ernst A, Eberhardt R, Wahidi M, et al: Effect of routine clopidogrel use on bleeding complications after transbronchial biopsy in humans. Chest 2006;129:734-737.

12 Fulkerson WJ: Current concepts. Fiberoptic bronchoscopy. N Engl J Med 1984;311:511515.

13 Babiak A, Hetzel J, Krishna G, et al: Transbronchial cryobiopsy: a new tool for lung biopsies. Respiration 2009;78:203-208.

14 Bjortuft O, Brosstad F, Boe J: Bronchoscopy with transbronchial biopsies: measurement of bleeding volume and evaluation of the predictive value of coagulation tests. Eur Respir J 1998;12:1025-1027.

15 Cordasco EM Jr, Mehta AC, Ahmad M: Bronchoscopically induced bleeding. A summary of nine years' Cleveland clinic experience and review of the literature. Chest 1991; 100:1141-1147. 